\title{
O PENSAMENTO HOLÍSTICO NA ESCOLA: O CASO DO PROJETO MEDIFTAÇÃO DE ITAPETININGA/SP
}

\author{
PENSAMIENTO HOLÍSTICO EN LA ESCUELA: EL CASO DEL PROYECTO \\ MEDIFTAÇÃO DE ITAPETININGA/SP (BRASIL)
}

\author{
HOLISTIC THINKING IN SCHOOL: THE CASE OF THE ITAPETININGA/SP \\ (BRAZIL) MEDIFTAÇÃO PROJECT
}

\author{
Debora Mota de SOUZA ${ }^{1}$ \\ Ivan FORTUNATO ${ }^{2}$ \\ Mateus Tófoli CORREA ${ }^{3}$
}

\begin{abstract}
RESUMO: Este artigo descreve e analisa a experiência de dois anos de existência do projeto medIFtação desenvolvido no Instituto Federal de São Paulo, campus de Itapetininga, no sudoeste do estado. Trata-se de um projeto emergente das necessidades de se apresentar aos estudantes do ensino médio algumas ferramentas de saúde mental para controle da ansiedade. Não obstante, a partir desse cenário, o projeto foi elaborado e tem sido conduzido além dessa proposta instrumental, elevando o sentido da meditação e do pensamento holístico como elementos de autoconhecimento e da compreensão da complexidade da vida. O texto foi organizado na forma de perguntas e respostas, com o propósito de tornar a explicação mais clara sobre especificidades do projeto. Espera-se, com a partilha deste relato, promover uma (auto)reflexão da meditação na educação e, quem sabe, encorajar outros projetos de natureza semelhante.
\end{abstract}

PALAVRAS-CHAVE: Meditação. Holístico. Ensino.

RESUMEN: Este artículo describe y analiza la experiencia de dos años de existencia del proyecto medIFtação desarrollado en el Instituto Federal de São Paulo (Brasil), campus Itapetininga, en el suroeste del estado. Es un proyecto que surge de la necesidad de presentar a los estudiantes de secundaria algunas herramientas de salud mental para controlar la ansiedad. Sin embargo, a partir de este escenario, se elaboró el proyecto y se ha llevado a cabo más allá de esta propuesta instrumental, elevando el sentido de la meditación y el pensamiento holístico como elementos de autoconocimiento y comprensión de la complejidad de la vida. El texto se organizó en forma de preguntas y respuestas, con el propósito de hacer más clara la explicación sobre las particularidades del proyecto. Se espera, al compartir esta historia, promover una (auto) reflexión de la meditación en la educación y, quién sabe, fomentar otros proyectos de similar naturaleza.

\section{PALABRAS CLAVE: Meditation. Holistic. Teaching.}

${ }^{1}$ Instituto Federal de São Paulo (IFSP), Itapetininga - SP - Brasil. Estudante do Ensino Médio Integrado. ORCID: https://orcid.org/0000-0002-2092-2235. E-mail: deboram.souza01@gmail.com

${ }^{2}$ Instituto Federal de São Paulo (IFSP), Itapetininga - SP - Brasil. Coordenadoria de Formação Pedagógica. Doutorado em Desenvolvimento Humano e Tecnologias (UNESP). ORCID: https://orcid.org/0000-0002-18707528. E-mail: ivanfrt@yahoo.com.br

${ }^{3}$ Universidade Federal de São Carlos (UFSCAR), Sorocaba - SP - Brasil. Mestrando no Programa de Pósgraduação em Ciência dos Materiais. ORCID: https://orcid.org/0000-0001-5274-3576. E-mail: mateustofolic@gmail.com 
ABSTRACT: This article describes and analyzes the experience of two years of existence of the medIFtation project developed at the Federal Institute of São Paulo, Itapetininga campus, in the southwest of the state. It is a project emerging from the need to present high school students with some mental health tools to control anxiety. Nevertheless, based on this scenario, the project was elaborated and has been carried out beyond this instrumental proposal, raising the sense of meditation and holistic thinking as elements of self-knowledge and understanding of the complexity of life. The paper was organized in the form of questions and answers, with the purpose of making the explanation clearer about the specifics of the project. It is hoped, by sharing this story, to promote a (self) reflection of meditation at school and, who knows, to encourage other projects of a similar nature.

\section{KEYWORDS: Meditación. Holístico. Enseñando.}

\section{Introdução}

[...] para trazar una circunferencia con un compás, lo primero que se hace es fijar el punzón en el papel y, luego se dibuja la circunferencia. No se hace al revés, aunque sea así como normalmente se procede ${ }^{4}$ (HÉRRAN, 2017, p. 30-31).

Este artigo descreve e analisa a experiência de dois anos de existência do projeto medIFtação desenvolvido no Instituto Federal de São Paulo, campus de Itapetininga, no sudoeste do estado. Trata-se de um projeto emergente das necessidades de se apresentar aos estudantes do ensino médio algumas ferramentas de saúde mental para controle da ansiedade. Não obstante, a partir desse cenário, o projeto foi elaborado e tem sido conduzido além dessa proposta instrumental, elevando o sentido da meditação e do pensamento holístico como elementos de autoconhecimento e da compreensão da complexidade da vida.

Embora a história de elaboração e condução do projeto já tenha sido registrada em outro texto (SOUZA; FORTUNATO; CORREA, 2020), buscamos aqui ampliar os significados mais profundos da meditação e sua correlação com sua prática constante no contexto de educação. De certa forma, as palavras reproduzidas na epígrafe apresentam uma eloquente síntese do que tencionamos expor: a meditação pode ser metaforicamente entendida como a busca pelo posicionamento da ponta seca do compasso, sem a qual não se consegue traçar uma circunferência.

Obviamente, não se trata de meditar para promover uma vida perfeita como a circunferência traçada por um compasso, pois as vicissitudes da existência tendem sempre a desestabilizar a ponta seca. Meditar, então, pode colaborar com a constante e necessária

${ }^{4}$ Tradução livre: [...] para desenhar um círculo com um compasso, a primeira coisa a fazer é fixar a ponta seca no papel e depois a circunferência é desenhada. Não é feito ao contrário, mesmo que normalmente seja assim. 
reestabilização desse simbólico eixo, pois nele nos apoiamos para serenar nossa mente, tornando os problemas e soluções mais visíveis, assim como permite encontrar os caminhos para uma vida mais saudável e feliz. Não obstante, meditar não é uma fórmula mágica, não diz respeito ao segredo de pensar positivamente, tampouco envolve ritos religiosos - embora meditar tenha, sim, relação com tudo isso.

Ao longo das páginas seguintes, almejamos revelar nossa compreensão de meditação como autoconhecimento, independente de qualquer fé ou crença que se tenha. Ainda, temos como objetivo demonstrar a importância de se trabalhar com um projeto voltado às práticas meditativas em um contexto de educação formal. Assim, o texto foi organizado na forma de perguntas e respostas, com o propósito de tornar a explicação mais clara sobre especificidades do projeto medIFtação, conduzido por nós desde o começo de 2019.

\section{Pergunta um: o que é meditação?}

A meditação é algo muito antigo, tendo sua provável origem nas filosofias orientais (MENEZES; DELL'AGLIO, 2009). De acordo com Barros e Luca (2004, p. 5) “meditar é buscar o silêncio que existe dentro de você, mas que se perde na agitação do dia-a-dia, na confusão de pensamentos e sentimentos". Talvez por causa dessa noção de "silêncio interior", muitas pessoas acreditam que a meditação só pode ser praticada a partir do pertencimento a alguma religião ou alguma crença espiritual; no entanto, de acordo com Fábrica (2019), ainda que a meditação esteja associada ao budismo como uma forma de alcançar o que se acredita, a prática não precisa estar associada ao caráter religioso ou a fé.

Baseados em nossa própria experiência, mas também em diversas leituras (GOLEMAN, 1999; DAVICH, 2007; SHAPIRO; SCHWARTZ; SANTERRE, 2009; CORREA; KURNICH; FORTUNATO, 2020; DANIELS, s/d), podemos dizer que a prática da meditação é bastante pessoal. As formas de alcançar o estado meditativo, de relaxamento e/ou de concentração são diferentes para cada pessoa, tendo em vista que a experiência de olhar para si, da percepção do momento presente e da tentativa de acalmar e organizar a mente é individual. Além disso, meditar é algo muito benéfico e recomendável no processo de autoconhecimento e autopercepção.

Para nós, meditar é entrar em um estado profundo e constante de si mesmo. O mencionado "estado meditativo" pode ser encontrado em diversas religiões, cultos, ritos, estilos de vida, entre outros, às vezes com outros nomes, embora sempre considerando como meditar o ato de focar em algo. Estudar, orar, ouvir música, ler um livro, ver um filme, 
participar de uma sessão de terapia, os segundos antes de cair no sono, um mestre de artes marciais fazendo suas respirações enquanto dá golpes dentre outros. Tudo isso tem diversas coisas em comum: foco, persistência, dificuldade de permanecer nesse estado por um longo tempo, concentração e resiliência. Tudo isso pode nos direcionar ao "estado meditativo".

Percebemos que para meditar é preciso perseverar, seja para se concentrar em sua respiração e em seu eu interior ou para focar em um livro didático, ou mesmo na letra de uma bela canção. Quando iniciamos um processo meditativo, nosso corpo e mente tentam lutar contra, seja uma coceira no nariz ou movimentos involuntários dos dedos dos pés, seja vontade de estalar o corpo ou de abrir os olhos, seja a facilidade em perder a linha de pensamento e acabar divagando sobre a vida. Por isso, existem técnicas conscientes voltadas para facilitar o alcance do estado meditativo, como a respiração controlada, a entoação de mantras (palavras ou frase significativa pronunciada de forma repetitiva), o controle da claridade do ambiente, o uso de incenso ou velas aromáticas, posições apropriadas e assim por diante - claro que, dependendo do contexto, cada um desses elementos adquire um sentido apropriado, principalmente se relacionado à fé ou crença, ou podem ser apena facilitadores do processo; é tudo questão de ponto de vista.

A dificuldade de se alcançar o estado meditativo, muitas vezes exigindo o uso dos artifícios externos, nos mostra que meditar está diretamente ligado ao controle do próprio corpo e da própria mente. Meditar, portanto, é estar em controle de si mesmo, reconhecendose no mundo, permitindo se conhecer e se perceber na complexidade da vida.

E esses foram os balizadores para se pensar, no final do ano de 2018, na criação de um projeto voltado à meditação como prática frequente. Embora o projeto tenha emergido de uma demanda específica da coordenação de um dos cursos de ensino médio, conforme relatamos em outro texto (SOUZA; FORTUNATO; CORREA, 2020), foi planejado para ser disponibilizado como lugar de meditação para toda comunidade do nosso campus do Instituto Federal.

\section{Pergunta dois: por que é importante meditar?}

O projeto a respeito da meditação no Instituto foi proposto, pois percebemos a importância de meditar ao compreender sua relação com o autocontrole, o autoconhecimento e a autopercepção. Dessa forma, cientes de si, podemos tomar as decisões com maior cautela, pensar com mais fluidez e aprender melhor sobre nós mesmos e sobre as informações do mundo. Quando meditamos com frequência, temos mais clareza sobre as coisas da vida e dos 
problemas pessoais, podendo localizar fontes de estresse, alguns disparadores de ansiedade ou, mais importante, identificar aspectos positivos da vida, permitindo também a definição de metas e a criação projetos de interesse pessoal.

No trabalho de Araujo et al. (2020) foram feitas avaliações com estudantes da área da saúde, que são conhecidos por serem alvos de estresse durante a graduação. Com isto, os autores aplicaram a meditação de atenção plena - uma das técnicas também utilizadas pelo nosso grupo durante os dois anos de trabalho no IFSP. O artigo apresenta um trabalho de nove semanas, durante as quais os estudantes praticavam e aprendiam sobre essa técnica de meditação. Ao verificarem os efeitos da meditação, por meio de um instrumento de medição de sentimentos ${ }^{5}$, Araujo et al. (2020) notaram significativo aumento em relação ao grupo de controle, que não participou das práticas meditativas. Seguindo essa ideia, a importância de meditar vem junto com a melhoria dos sentimentos em relação à própria vida; se em nove semanas o estudo de Araujo et al. (2020) apontou significativas mudanças, podemos inferir que a meditação como um hábito seja fundamental para conquista e manutenção do bemestar.

No livro “A arte da meditação", Daniel Goleman (1999) faz uma relação interessante entre a meditação, o estresse e a ansiedade, afirmando que pessoas ansiosas enfrentam os acontecimentos da vida como se fossem crises. Isso tende a desencadear um aumento de tensão a cada pequeno acontecimento, sendo vistos como ameaças constantes. A ideia do autor é propor a meditação como forma de passar por esses momentos com as energias necessárias para enfrentá-los. "A pessoa que medita regularmente”, afirma Goleman (1999, p. 12), "lida com o estresse de modo a romper a espiral da reação de enfrentamento ou fuga. Ela relaxa com muito mais frequência do que a que não medita, após um desafio ter sido superado".

Além disso, o momento de autopercepção que a meditação proporciona permite acalmar e organizar os nossos pensamentos ao ponto de priorizarmos o que precisa ser pensado naquele momento. Afinal, muitas vezes pensamos em excesso naquilo que está fora do nosso controle, como o passado e o futuro. A meditação é uma forma de perceber o que de fato temos controle, o presente. Essa percepção impacta diretamente na forma como lidamos com as situações, com autoconfiança e sensação de controle sobre as próprias decisões diante da percepção do que de fato está acontecendo.

${ }^{5}$ O referido instrumento foi o PANAS (Positive Affect Negative Affect Scale), desenvolvido por Watson e Clark (1985). 
Contudo, não há uma única razão para meditar, podendo-se meditar apenas por meditar, como já escrevemos em outro momento: "não há nenhum objetivo a ser alcançado com a meditação, pois a meditação é o próprio objetivo" (CORRÊA; KURNICH; FORTUNATO, 2020, p. 243).

\section{Pergunta três: como a meditação pode ajudar os estudos e os estudantes?}

Notamos, a partir da nossa experiência como docentes e estudantes, que um dos problemas mais recorrentes ao estudar qualquer tema é a falta de concentração e a capacidade de se manter focado na leitura ou na resolução de um exercício. Dessa maneira, vimos que meditar ajuda a encontrar foco, assim como ajuda a tranquilizar a mente para pensar sobre aquilo que efetivamente podemos ter algum controle.

Além disso, meditar constantemente ajuda a encontrar um ritmo respiratório mais adequado à oxigenação do organismo, auxiliando no controle da ansiedade - estudar ansioso tende a ser um grande problema, seja pelo desvio da atenção, seja pela autocobrança em assimilar todos os conteúdos de forma plena e imediata, dentre outros. Afinal, a escola e a universidade podem se tornar ambientes de grande pressão emocional e psicológica, ao cobrar notas altas e/ou colocar os estudantes cara a cara com a ideia de sociedade competitiva, na qual é preciso muito esforço físico e mental para superar aos demais e, assim, vencer na vida. Nunca é demais relembrar a "lei de Charlie Brown" a respeito da educação escolar, muito bem retrata na crônica escrita por Rubem Alves (1994):

Sabe por que temos que tirar boas notas na escola? Para passarmos do primário para o ginásio. Se tirarmos boas notas no ginásio, passamos para o colégio e se no colégio tirarmos boas notas, passamos para a universidade, e se, nesta tirarmos boas notas, conseguimos um bom emprego e podemos casar e ter filhos para mandá-los à escola, onde eles vão estudar um monte de coisas para tirar boas notas e [...] (ALVES, 1994, p. 16).

Essa fórmula tende, de fato, a provocar intensa pressão emocional, psicológica e até física sobre os estudantes, pois passa a ser entendida da seguinte maneira: sem as boas notas, não há universidade e sem universidade não há bons empregos; e sem os bons empregos, não se pode desfrutar da vida. Claro que essa fórmula é apenas uma alegoria da vida escolar, não representando efetivamente seu cotidiano, mas, carrega um fundo de verdade capaz mesmo de provocar angústia e ansiedade nos estudantes, fazendo-os pensarem insistentemente no futuro. E, como vimos, não temos controle algum sobre o futuro. 
Assim, como a meditação envolve concentração e relaxamento ao mesmo tempo, ela pode apresentar ótimas técnicas para estudantes, inclusive para aqueles que estão se preparando para uma prova, como vestibulares e afins. Se início dos estudos pode ser momento de empolgação e euforia, envolvendo novos planos e expectativas para o futuro, a manutenção de sua rotina diária exige certo esforço físico e mental, podendo levar ao esgotamento e consequente diminuição do foco e da. Por isso, é imprescindível que sejamos gentis (conosco), ao ponto de compreender que os acontecimentos da vida não são lineares, que as coisas muito provavelmente não sairão exatamente como a gente imagina e, apesar de tudo isso, está tudo bem; olhar para si e se entender nesse processo é fundamental, principalmente, para a sanidade mental.

Nessa perspectiva, a meditação pode ser adotada diariamente antes de iniciar os estudos, fechando os olhos, respirando conscientemente e aos poucos incluir outras técnicas como os mantras, como forma de autoafirmação, como, por exemplo, "eu consigo, eu posso, está feito", usado bastante ao longo do nosso projeto medIFtação. Trata-se de se buscar um estado intensificado de atenção, pois "esse aguçamento da atenção dura além da própria sessão de meditação" (GOLEMAN, 1999, p. 14), ou seja, o estado meditativo tende a permanecer mesmo depois do momento reservado à prática da meditação.

\section{Pergunta quatro: qual a diferença entre meditar sozinho e em grupo?}

Ao longo do desenvolvimento do projeto, notamos que a meditação em grupo é considerada mais fácil de ser realizada por diversos fatores. Primeiro pela motivação, pois se está em um grupo de colegas, amigos ou conhecidos que, juntos, têm o foco de aprender e desenvolver as habilidades de meditação. Com isso, o engajamento conjunto do grupo pode motivar cada um dos seus integrantes, individualmente. Um segundo ponto que torna a meditação em grupo mais fácil é a possibilidade de uma meditação guiada por um dos seus membros do grupo. Isso porque, obedecer a comandos de relaxamento, respiração e confiança é mais confortável do que criá-los sozinhos, enquanto batalhamos com nosso próprio corpo e mente para conseguir alcançar o estado meditativo.

Meditar sozinho, em comparação à meditação em grupo, pode ser um pouco mais difícil, principalmente, pois, como já descrito neste texto, o corpo e a mente tendem a dar sinais de incômodo, sejam coceiras discretas ou o incessante lembrete das coisas por fazer, com prazos curtos. Assim, diferente de uma meditação guiada por um terceiro, quando estamos sozinhos, fica mais fácil para a nossa mente nos levar para memórias distantes, 
lembranças do passado e expectativas de um futuro, ou seja, fatores que se tornam obstáculos durante a prática. Existem estratégias para contornar esses desconfortos, como a respiração lenta e ritmada, ou a já referida entoação de um mantra. Ainda, pode-se fazer uso auxiliar de objetos chamados de holísticos, que trazem calma e conforto, tais como o incenso ou a chama de uma vela, ou mesmo um recipiente com água e plantas.

Apesar das facilidades apontadas para a meditação coletiva, há quem prefira estar sozinho para esse momento, em silêncio, em um ambiente de preferência. O importante é entender que, independentemente, de como e/ou onde se medita, as experiências são sempre únicas e, com o tempo e a persistência, cada um encontra a melhor maneira para si.

\section{Pergunta cinco: qual a importância de um projeto de meditação dentro de uma instituição de ensino?}

Ao trazer a discussão e a prática para uma instituição de ensino, podemos desenvolver e adaptar meios eficazes de tornar a meditação parte da vida de discentes e docentes, trazendo maior conforto, qualidade de vida e benefícios à comunidade educacional no geral.

De acordo com Fábrica (2020), muitos são os benefícios da meditação na escola, dentre eles, o reconhecimento do potencial autoconhecimento e, consequentemente, da autoestima, o desenvolvimento da independência nas escolhas, assim como lidar com os sentimentos de frustração, medo e raiva. Portanto, espaços como o medIFtação permitem que os participantes se sintam acolhidos de alguma forma, tendo em vista que, muitas vezes, a própria Instituição é uma das responsáveis por desencadear o estado de estresse e ansiedade. Por isso é importante a criação de espaços que ofereçam às pessoas, sobretudo para aquelas que passam muito tempo dentro da Instituição, um momento de relaxamento, descanso físico e mental.

Nesse sentido, o medIFtação é um espaço criado intencionalmente para promoção do bem-estar coletivo, pois temas como pressão, ansiedade e estresse relacionados aos estudos (e outras contingências da vida) são tratados de forma consciente, livre e bastante honesta entre os participantes. Além disso, muitos estigmas sobre a meditação são desconstruídos e ressignificados, a começar pelo acesso às pesquisas científicas que corroboram para o estímulo do pensamento crítico sobre temas relacionados ao chamado holismo e aos próprios sentimentos e emoções. 


\section{Pergunta seis: quais os maiores desafios de um projeto deste tipo?}

Apesar dos benefícios apontados, diversos problemas e barreiras podem ser encontrados durante o projeto, dentre os quais podemos listar a falta de comprometimento pela descrença do método, a falta de tempo para mobilizar e engajar um maior número de pessoas para participar da meditação e situações meditativas e a visão conservadora de diversos acadêmicos ao considerarem a meditação como uma pseudociência ou um ato de fé.

Fato é que muitas pessoas acreditam que a meditação só é praticada a partir do pertencimento a alguma religião; no entanto, de acordo com Fábrica (2019), ainda que esteja associada ao budismo (e outras filosofias orientais) como uma forma de alcançar o que se acredita, a prática não necessariamente precisa estar associada ao caráter religioso. Segundo a autora, isso torna a meditação atemporal e que alcança muitas pessoas, independente do lugar e da crença. Além disso, segundo Goleman (1999), é possível perceber que as pessoas que meditam com frequência tendem a ser, geralmente, mais ativas do que as que não meditam. "A meditação treina a capacidade de prestar atenção. Isso a diferencia de muitas outras formas de relaxamento que permitem que a mente divague à vontade" (GOLEMAN, 1999, p. 13).

Durante o tempo de execução do projeto medIFtação, podemos incluir como entraves a dificuldade de se encontrar tempo, durante a semana, para reunir docentes, discentes, técnicos e outros interessados na prática da meditação. A existência de um local ideal também foi certo entrave, pois, embora tenhamos afirmado ser possível meditar em qualquer lugar, também explicamos que elementos holísticos, além de música e iluminação adequadas, tornam o processo mais amistoso aos principiantes. Aos poucos, esses dois entraves foram sendo contornados, até sermos surpreendidos pela pandemia da Covid-19, em março de $2020 \ldots$

\section{Pergunta sete: qual o papel da meditação no contexto de isolamento social da pandemia?}

Meditar pode auxiliar no desenvolvimento progressivo do bem-estar mental, físico e emocional (MENEZES; DELL'AGLIO, 2009). Por outro lado, estamos num momento contrário ao bem-estar, pois estamos vivendo uma pandemia de Covid-19, trazendo dor e sofrimento de forma coletiva a praticamente todos os lugares do planeta. Muito além dos desastres causados à saúde física, a pandemia tem provocado intenso mal-estar emocional e psicológico. Como podemos observar em vários sites de notícias como $\mathrm{R}^{6}, \mathrm{Uol}^{7}, \mathrm{CNN}^{8} \mathrm{e}$

${ }^{6}$ Disponível em: https://encurtador.com.br/dhG29. Acesso em: 22 nov. 2020.

${ }^{7}$ Disponível em: https://encurtador.com.br/ftwO0 Acesso em: 22 nov. 2020. 
Diário do Nordeste $^{9}$, os casos de depressão, ansiedade e estresse cresceram em torno de $70 \%$ a 90\% em comparação ao mesmo período nos anos anteriores.

Com a declaração oficial da Organização Mundial da Saúde sobre o estado pandêmico devido ao novo coronavírus (SARS-CoV-2) em março de $2020^{10}$, muitas mudanças se fizeram necessárias para contenção do vírus. O isolamento social tornou-se primordial e muitos que tiveram o privilégio de poder ficar em casa, assim o fizeram. No entanto, é fato que esse isolamento, ainda que extremamente necessário, desencadeou diferentes impactos psicológicos nas pessoas, sobretudo pela mudança na rotina e perda da liberdade. De acordo com Schmidt et al. (2020) o medo de ser infectado e de infectar outras pessoas, a sensação de perda de controle, e a imprevisibilidade sobre o término da pandemia, são fatores que impactam diretamente na saúde mental do indivíduo.

Nesse sentido, a meditação pode resgatar essa sensação de controle, a partir da respiração consciente, da autopercepção, da concentração no momento presente, na organização da mente em prioridades de pensamento, na tentativa de evitar preocupações que fogem do nosso controle, além disso, manter a calma em um momento onde tudo é ainda mais incerto.

Longe de apresentar a meditação como solução, o que estamos propondo é uma forma auxiliar de se (auto)(re)organizar diante um contexto novo, nada favorável à vida. Assim como argumentam Menezes e Dell'aglio (2009), ao analisarem experiências subjetivas da meditação, benefícios diversos de ordem cognitiva, emocional, física, espiritual e social podem ser elencados do constante hábito de meditar. Segundo as autoras, portanto, "pode-se concluir que a experiência da meditação se reflete positivamente em diferentes domínios da vida do praticante [...] concorrendo para um desenvolvimento psicológico saudável” (p. 572).

Entendemos, então, a meditação como um coadjuvante positivo à preservação da saúde mental neste contexto perverso de pandemia. Por isso, optamos por manter a constância do projeto medIFtação por meio da rede social Instagram ${ }^{\circledR}$, no perfil /mediftacao, com postagens bem-estar e ansiedade, além de encontros regulares virtuais pelo GoogleMeet ${ }^{\circledR}$.

${ }^{8}$ Disponível em: https://encurtador.com.br/AILS3. Acesso em: 22 nov. 2020

${ }^{9}$ Disponível em: https://encurtador.com.br/rtSWX. Acesso em: 22 nov. 2020.

${ }^{10}$ Disponível em: https://www.bbc.com/portuguese/geral-51842518. Acesso em: 18 set. 2020. 
Pergunta oito: quais os mais importantes resultados obtidos ao longo de dois anos de projeto?

O primeiro resultado substancial do medIFtação foi a própria aprovação do projeto para ser desenvolvido dentro do Instituto, pois, como vimos, um dos obstáculos à meditação na educação formal é seu estigma de não-ciência. Nessa mesma direção, consideramos como positivo o fato de o projeto ter sido contemplado por dois anos consecutivos com bolsa de fomento da própria instituição. Esses dois elementos formam base sólida para todas as atividades realizadas neste biênio 2019-2020.

Das atividades realizadas no encontro semanal de meditação no Instituto (e sua continuidade pelo mundo virtual), envolvendo uma média de 30 estudantes e docentes de forma positiva pelo grupo, trazendo assim mais tranquilidade e, quem sabe, até mesmo mais uma possibilidade para se alcançar o controle e equilíbrio em suas vidas. Diversos relatos de agradecimento dos participantes corroboram com essa afirmação, motivando-nos a manter e continuar o projeto. Relatos tais como o quanto que os encontros contribuíam não só no momento, mas, também no decorrer da semana durante as aulas, as atividades e as provas; assim como, relatos sobre como a prática era entendida (como religiosa, por exemplo) antes de vê-la dentro da Instituição como uma técnica benéfica e independente de qualquer fé ou crença.

Todo esse envolvimento ao longo de 2019 nos levou à organização do Primeiro Encontro de Práticas Holísticas e Saúde Mental no Instituto. Um evento muito importante, primeiramente pelo seu pioneirismo no campus e, principalmente, pela participação e engajamento nas palestras e práticas não só da comunidade interna, como também da comunidade externa à Instituição. Já no ano de 2020, os resultados foram muito mais no desenvolvimento de pesquisa do que resultados práticos, tendo em vista que a experiência com o ambiente virtual foi bem difícil, ao considerar que a participação dos alunos diminuiu bastante.

Além disso, se considerarmos também as informações já recolhidas e escritas sobre o projeto, temos duas apresentações importantes em congressos, no ano de 2020 - o Congresso de Inovação, Ciência e Tecnologia do IFSP (CONICT), que é um congresso envolvendo todos os campus do estado de São Paulo, e o Simpósio Internacional de Iniciação Científica e Tecnológica da USP (SIICUSP), que é um evento internacional promovido pela Universidade de São Paulo. Somam-se aos congressos dois capítulos de livros publicados (SOUZA; FORTUNATO; CORRÊA, 2020; CORRÊA; KURNICH; FORTUNATO, 2020), fortalecendo a ideia de que a meditação deve ser incorporada nos Anais das ciências, inclusive na educação 
- não como instrumento, como já foi afirmado em outro ensaio (FORTUNATO, 2020), mas como processo de autoconhecimento.

\section{Pergunta nove: por que deve continuar?}

De tudo o que foi relatado ao longo deste artigo, não nos resta dúvidas de que devemos continuar batalhando pela manutenção e ampliação do projeto medIFtação. Se existe a possibilidade de controle da ansiedade e melhora da concentração, então precisamos envolver mais estudantes, professores e demais interessados nas práticas do projeto. Se há algo de melhoria na qualidade de vida na constante prática voltada à conquista do estado meditativo, então vale a pena ampliar seu alcance, beneficiando mais pessoas.

A continuidade do projeto faz-se necessária na Instituição, pois é uma das formas de proporcionar à comunidade um espaço no qual se possa encontrar meios para promover autoconhecimento e fortalecer os fatores de proteção para lidar com os diferentes acontecimentos da vida - incluindo o próprio grupo como um coletivo que trabalha sem julgamentos e com o único objetivo de promover o bem-estar. Continuar é importante, pois a saúde mental precisa ser uma pauta a ser discutida com mais frequência, não apenas dentro do nosso Instituto, mas em todos os lugares.

\section{Considerações transitórias envolvendo meditação, o projeto e a atual conjuntura}

Ao considerar os benefícios proporcionados pela meditação, primeiramente pelo fato de nos encorajarmos para uma viagem dentro de nós mesmos é, sem dúvidas, um caminho para o autoconhecimento, autopercepção, autoconfiança etc.

Como foi mencionado, a prática constante não promove uma existência plena, tendo em vista a inconstância dos eventos da vida. Contudo, pela meditação, temos uma forma de estimularmos hábitos essenciais para que possamos enxergar com mais clareza nossos pensamentos e organizá-los de acordo com a nossa prioridade. Reconhecer quais são os níveis de prioridades de cada pensamento é um ato de gentileza para com nós mesmos, potencializado pela meditação.

É perceptível o quanto que práticas meditativas são subjetivas, pois as experiências são únicas, justamente pela forma como cada pessoa vivencia seu momento. O ano de 2020, inegavelmente, nos trouxe diversas reflexões acerca da ansiedade, tendo em vista que o 
isolamento social resultou na sensação de perda de liberdade, quebra de expectativas, juntamente com a incerteza e ao mesmo tempo esperança de um futuro melhor.

Nesse sentido, ainda que as formas de lidar com o estresse e a ansiedade sejam diferentes de pessoa para pessoa, esse fato não exclui a existência de pontos em comum entre os participantes sobre um mesmo assunto ou sentimento; por esse motivo vimos que a condução do medIFtação como espaços de trocas de experiências (sonhos, angústias etc.) é bastante significativo aos envolvidos, sobretudo por ser um momento de escuta e de compreensão e neste caso, dentro de uma das bases da estrutura do país: a educação.

AGRADECIMENTOS: Ao Instituto Federal de São Paulo, campus Itapetininga, pela bolsa de estudos destinada ao projeto medIFtação nos anos 2019 e 2020, além da cessão de uma sala para encontros semanais e toda infraestrutura para a realização do Encontro de Práticas Holísticas, em 2019.

\section{REFERENCIAS}

ALVES, R. A alegria de ensinar. São Paulo: ARS poética, 1994.

ARAUJO, A. C. et al. Efeitos de um curso de meditação de atenção plena em estudantes da saúde no Brasil. Acta Paul Enferm., v. 33, eAPE20190170, p. 1-9, 2020. DOI:

http://dx.doi.org/10.37689/acta-ape/2020AO0170

BARROS, L.C.; LUCA, M. Meditação. São Paulo: Editora Caras, 2004.

CORREA, M. T.; KURNICH, G. P.; FORTUNATO, I. Psicologia Positiva e lazer: a meditação alvitrada. In: TEODORO, A. P. E. G. et al. (Org.). Atividades de Aventura no Congresso Brasileiro de Atividades de Aventura (CBAA) e Congresso Internacional de Atividades de Aventura (CIAA). São Paulo: Editora Supimpa, 2020. p. 243-246.

DANIELS, R. E. A meditação. Disponível em: https://www.amorc.org.br/a-meditacao/. Acesso em: 7 nov. 2020.

DAVICH, V. N. O melhor guia para a meditação. São Paulo: Pensamento, 2007.

FÁBRICA, J. Prática de meditação nas escolas: um estudo sobre as percepções de crianças, encarregados de educação e profissionais da educação em contexto de Educação Pré-Escolar e Ensino do $1^{\circ}$ Ciclo do Ensino Básico. Orientadora: Clementina Nogueira. 2019. $177 \mathrm{f}$.

Dissertação (Mestrado em Educação Pré-Escolar) - Universitário de Almada Escola Superior de Educação Jean Piaget, Almada, 2019.

FORTUNATO, I. Coisas que gostaria de trabalhar na formação de professores de ciências e matemática, mas não sei como. Rev. Int. de Pesq. em Didática das Ciências e Matemática 
(RevIn), Itapetininga, v. 1, e020013, p. 1-13, 2020.

GOLEMAN, D. A arte da meditação: um guia para a meditação. Rio de Janeiro: Sextante, 1999.

HERRÁN, A. Para una Pedagogía radical e inclusiva. Revista Boletin Redipe, v. 6, n. 7, p. 24-32, 2017.

MENEZES, C. B.; DELL'AGLIO, D. D. Por que meditar? A experiência subjetiva da prática de meditação. Psicologia em Estudo, Maringá, v. 14, n. 3, p. 565-573, 2009. Disponível em: https://www.scielo.br/pdf/pe/v14n3/v14n3a18. Acesso em: 10 set. 2020.

SHAPIRO, S. L.; SCHWARTZ, G. E. R.; SANTERRE, C. Meditation and Positive Psychology. In: SNYDER, C. R.; LOPEZ, S. (Org.) The Oxford Handbook of Positive Psychology. New York: Oxford University Press, 2009. p. 632-645.

SCHMIDT, B. et al. Saúde mental e intervenções psicológicas diante da pandemia do novo coronavírus (COVID-19). Estudos de Psicologia, Campinas, v. 37, e200063, 2020. DOI: http://dx.doi.org/10.1590/1982-0275202037e200063

SOUZA, D. M.; FORTUNATO, I.; CORREA, M. T. Relato sobre o projeto pensamento holístico aplicado ao ensino: meditação, mantras e outras técnicas. In SHIGUNOV NETO, A. et al. (Org.). 10 anos de atuação do campus Itapetininga do IFSP: gerando crescimento e oportunidades para a cidade e região. Itapetininga: Edições Hipótese, 2020. p. 169-174.

WATSON, D.; CLARK, L. Development and validation of brief measures of positive and negative affect: the PANAS scales. Journal of Personality and Social Psychology, v. 54, n. 1, p. 1063-1070, 1985.

\section{Como referenciar este artigo}

SOUZA, D. M.; FORTUNATO, I.; CORREA, M. T. O pensamento holístico na escola: o caso do projeto mediftação de Itapetininga/SP. Temas em Educ. e Saúde, Araraquara, v. 16, n. 2, p. 675-688, jul./dez. 2020. e-ISSN 2526-3471. ISSN 1517-7947. DOI: https://doi.org/10.26673/tes.v16i2.14590

Submetido em: $30 / 05 / 2020$

Aprovado em: 15/08/2020

Publicado em: 27/08/2020 